\title{
Research on Ancillary Service Compensation Mechanism of Generation Rights Trade between Renewable Energy and Conventional Energy
}

\author{
Tian Xia ${ }^{1,2, a}$, Yongxiu He ${ }^{1, b}$, Dong Song ${ }^{1, c}$, Qian Chen ${ }^{1, d}$ \\ ${ }^{1}$ North China Electric Power University, China \\ ${ }^{2}$ State Grid Gansu Electric Power Corporation, China \\ a462985708@qq.com, byxhe0941@sina.com, chdsongdong@163.com, d1559065389@qq.com
}

\begin{abstract}
Keywords: Generation rights trade; Ancillary service; Compensation mechanism; Renewable energy consumption
\end{abstract}

Abstract: In order to promote the consumption of renewable energy and adjust energy structure, it is an effective way to use generation rights trade between renewable energy and conventional energy. Reasonable benefits can promote their enthusiasm to participate in the generation rights trade, so research on ancillary service compensation mechanism of generation rights trade between renewable energy and conventional energy is imminent. By analyzing the mode of generation rights trade between renewable energy and conventional energy and clarifying the responsibilities and obligations of all participants, this paper designed compensation mechanism of ancillary service and analyzed cost compensation under different allocation methods, thus seeking for a reasonable compensation mechanism of ancillary service, which can provide a reference for the generation rights trade between renewable energy and conventional energy.

\section{Introduction}

Under the background of power system reform, the transaction model between power producers and users will show a trend of diversity. Market-oriented participation of various power producers is getting higher and higher. As market participants, renewable energy companies will have more flexible participation and cooperation means to promote consumption of renewable energy ${ }^{[1-2]}$. Generation rights trade between renewable energy and conventional energy is an important way to solve the problem of renewable energy consumption ${ }^{[3]}$. With the large-scale renewable energy access, the traditional transaction models and compensation mechanisms have been unable to adapt and meet the demand of promoting renewable energy consumption. Therefore, by analyzing the mode of generation rights trade between renewable energy and conventional energy and clarifying the responsibilities and obligations of all participants, it is of great signification to design ancillary service compensation mechanism for promoting the consumption of renewable energy and adjusting energy structure ${ }^{[4-5]}$.

\section{Analysis of generation rights trade between renewable energy and conventional energy}

In order to solve the problem of wind and photovoltaic curtailment severely and promote the development of renewable energy such as wind power generation, solar power generation, biomass power generation, geothermal power generation and ocean power generation, renewable energy integration is divided into two parts: guaranteed acquisition electricity and market transaction electricity. The part of guaranteed acquisition electricity ensures full amount of electricity on-grid according to the benchmark electricity price by planning the annual power generation priority and signing a priority power generation contract with the State Grid corporation; the part of market transaction electricity obtains power generation contracts by participating in competition, power grid enterprises implement the power generation contracts in accordance with the principle of priority scheduling. According to the power system reform and impact of generation rights trade by policies related to renewable energy, this paper designed a model of generation rights trade between renewable energy and conventional energy under the new situation, which is shown in Fig.1: 


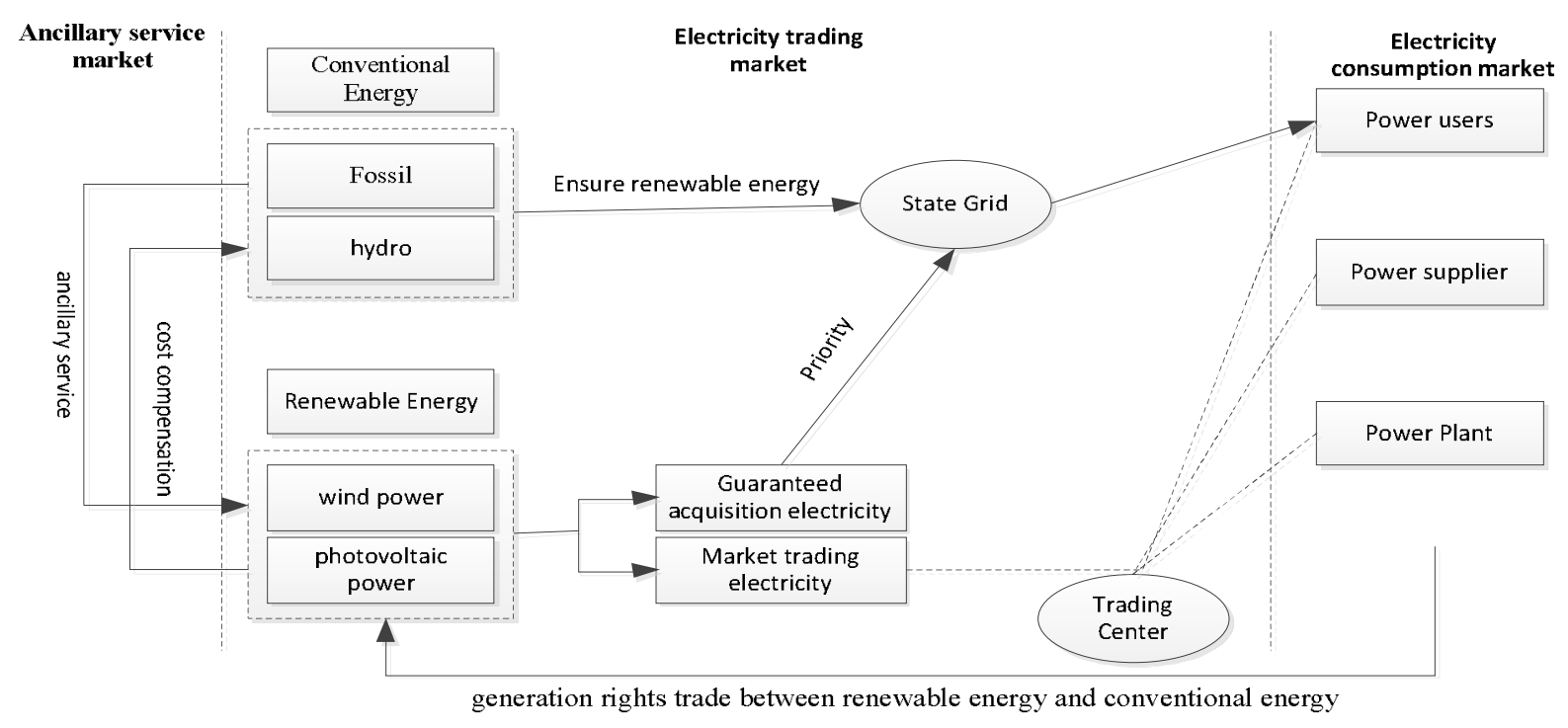

Fig.1 Generation Rights Trade between Renewable Energy and Conventional energy

From the Fig.1, it can be seen that renewable energy enterprises can make direct market transaction with electricity selling companies, power users and self-generation power plants to promote the consumption of renewable energy besides the guaranteed acquisition electricity. While conventional energy generation companies ensure the minimum power generation of renewable energy, at the same time they should provide ancillary services for renewable energy enterprises. Renewable energy enterprises make appropriate compensation in form of benefits sharing to the conventional energy generator for the provision of ancillary service in accordance with incremental benefits of renewable energy enterprises after generation rights trade. Beyond guaranteed acquisition electricity of renewable energy, the market trading electricity makes autonomous transactions by renewable energy enterprises and conventional energy generators in a unified trading platform. Power grid enterprises and electricity selling enterprises should actively promote the consumption of renewable energy, thereby promoting generation rights trade between renewable energy and conventional energy.

\section{Research on cost compensation of ancillary service}

\section{Design of ancillary service compensation mechanism}

The key issue of generation rights trade between renewable energy and conventional energy is the design of ancillary service compensation mechanism. In order to promote the consumption of renewable energy, while giving priority to renewable energy on grid, conventional energy generators should provide ancillary service for renewable energy enterprises. The compensation price of renewable energy to conventional energy is related with the incremental benefits of generation rights trade and the extent of both sides' contribution. Namely compensation mechanism is a game of allocation of incremental benefits after cooperation between renewable energy enterprises and conventional energy enterprises. Therefore, the allocation model of benefits can be used to quantify the compensation mechanism in the process of design of compensation mechanism for generation rights trade, which is shown in Fig.2. 


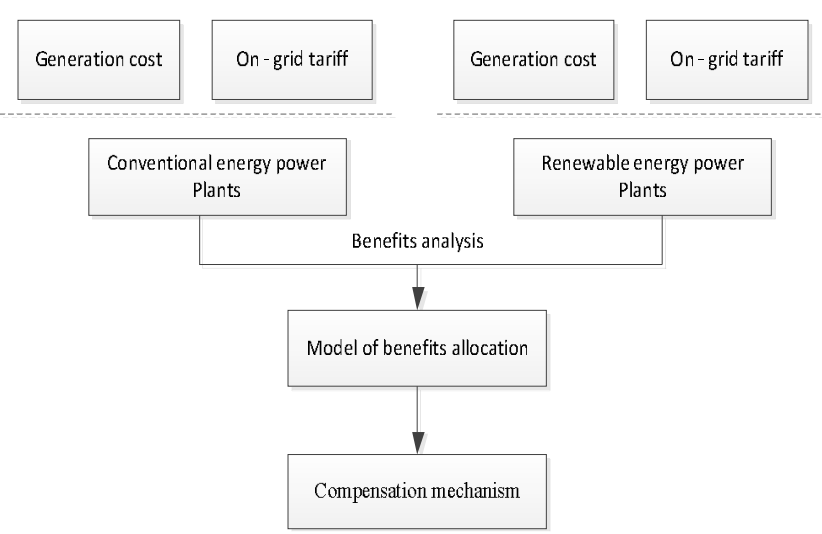

Fig.2 Compensation Mechanism of Ancillary Service

\section{Analysis of ancillary service allocation model}

1 ) EANS ( equal allocation of non-separable cost ) model

EANS model is that in addition to the participants' separable cost, the remainder is non-separable and each participant bears its own separable cost, and then sharing the non-separable cost equally among the participants. The formula of EANS is shown as follows:

$$
x_{i}=\frac{1}{n}\left[c(N)+\sum_{j \in N} c(N \backslash j)\right]-c(N \backslash i)
$$

where $c(N)$ is the total cost of participants; $c(N \backslash i)$ is the total cost in addition to the participant $i$.

\section{2 ) Shapley Value model}

The EANS model ignores alliances other than the major leagues and groups that include (n-1) participants, and these alliances that contain fewer participants are likely to have an impact on the results of the allocation. While Shapley Value shares the cost in terms of the participants' marginal contribution, namely the cost to be allocated by participants should be equal to the average marginal contribution of the alliances it participates in, which is shown in the formula:

$$
x_{i}=\sum p_{1} \times \Phi_{i}(S)=\sum \frac{(s-1) !(n-s) !}{n !} \times\{V(S)-V(S \backslash i)\}
$$

where ${ }^{x_{i}}$ is the cost allocated by participant $i ; n$ is the total number of alliances; $s$ is the number of participants; ${ }^{V}(S)$ is the total cost of alliances; ${ }^{V}(S \backslash i)$ is the cost when participant $i$ does not participate in the alliance.

\section{Case analysis}

\section{Analog data}

1) Analysis of peaking demand for wind power

According to the compensation results of Xinjiang Power Grid "two rules" in 2016, the assessment scores of three wind farms are shown in the table below. Assuming that $80 \%$ of the assessment score of each wind farm comes from the peaking ancillary service, then according to the assessment standard of peaking ancillary service, this paper estimated three wind farms' peaking demand, which is shown in Table.1.

Table.1 EstimationTable of Peaking Demand for Wind Farm

\begin{tabular}{|c|c|c|}
\hline Name of wind farm & Assessment score & Peaking demand ( MWh ) \\
\hline wind farm 1 & 30.3 & 121.2 \\
\hline wind farm 2 & 66.7 & 266.8 \\
\hline wind farm 3 & 44.2 & 176.8 \\
\hline
\end{tabular}


2) Analysis of influence on peaking demand as multiple wind farms combined to the grid

When multiple wind farms combined to the grid, there is smoothing effect among the wind power output. Therefore, the total cost of ancillary service for wind farms combined to the grid is affected by the time series correlation of different wind farms' output ${ }^{[7]}$, which is shown in the following table. $\rho$ is the times series correlation coefficient of output curve of two wind farms. $c_{1}, c_{2}$ is respectively the cost of ancillary service led by wind farm 1 and wind farm 2 which is access to the grid alone. $c$ is the total cost of ancillary service due to wind farm 1 and wind farm 2 joint access to the grid.

Table.2 Relationship between Correlation Coefficient of Wind Farm and Ancillary Service

\begin{tabular}{|c|c|}
\hline Correlation coefficient & ancillary service cost relationship \\
\hline$\rho=1$ & $c=c_{1}+c_{2}$ \\
\hline$\rho=-1$ & $c<c_{1}+c_{2}$ \\
\hline$-1<\rho<1$ & $c<c_{1}+c_{2}$ \\
\hline
\end{tabular}

It can be seen from the Table. 2 that there is smoothing effect between the two wind farms when the time series correlation coefficient of the output of the two wind farms is not 1 (the output time of the two wind farms is identical), Therefore, we can simulate the amount of peaking ancillary service under different joint sizes of the three wind farms, which is shown in Table.3.

Table.3 Peaking Demand with Wind Farms Connected to the Grid

\begin{tabular}{|c|c|}
\hline Item & Peaking demand ( MWh ) \\
\hline wind farm 1 & 121.20 \\
\hline wind farm 2 & 266.80 \\
\hline wind farm 3 & 176.80 \\
\hline wind farm 1+wind farm 2 & 349.20 \\
\hline wind farm 2+wind farm 3 & 377.06 \\
\hline wind farm 1+wind farm 3 & 262.24 \\
\hline wind farm 1+wind farm 2+wind farm 3 & 451.84 \\
\hline
\end{tabular}

Analysis of ancillary service cost under different allocation methods

According to the peaking demand of Ttable.3, the comparison of ancillary service cost of wind farms under different allocation methods is calculated according to formula 3 and formula 4 , which is shown in Table.4 and Fig.3.

Table.4 Comparison of Ancillary Service Cost of Each Wind Farm under Different Allocation Methods

\begin{tabular}{|c|c|c|c|}
\hline Item & the current cost & EANS Value & Shapley Value \\
\hline wind farm 1 & 24240 & 20610.67 & 18660 \\
\hline wind farm 2 & 53360 & 43574.67 & 44702 \\
\hline wind farm 3 & 35360 & 26182.67 & 27006 \\
\hline
\end{tabular}

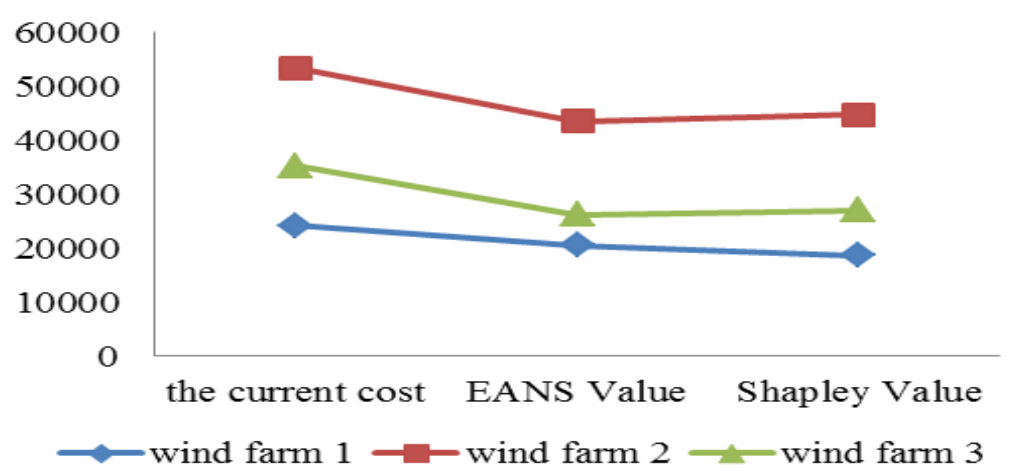

Fig.3 Comparison of Ancillary ServiceCost of Each Wind Farm under Different Allocation Methods 
As can be seen form Table.4 and Fig.3, the total cost of ancillary service due to the combined access of multiple wind farms is less than the sum of ancillary service cost for their separate access to grid. In addition, the scale of the three wind farms is wind farm 2> wind farm 3> wind farm 1 . The cost of both wind farm 2 and wind farm 3 in EANS allocation model is lower than that in Shapley Value allocation model. While the cost of wind farm 1 in EANS allocation model is higher than that in Shapley Value allocation model.

\section{Conclusions}

Under the background of power system reform, this paper analyzed mode of generation rights trade between renewable energy and conventional energy, clarified the responsibilities and obligations of each participant and then designed compensation mechanism of ancillary service. The case showed that cooperative access of several wind farms is helpful to reduce the cost of ancillary service, and the allocation of EANS is advantageous to large and medium scale wind farms, while the allocation of Shapley Value is more favorable for small wind farms. The design of compensation mechanism can not only improve their enthusiasm to participate in the generation rights trade, but also can promote the consumption of renewable energy, which is of great significance to adjust energy structure.

\section{Acknowledgements}

The work described in this paper was supported by research grant from science and technology projects of State Grid Electric Power Corporation in China.

\section{References}

[1] ZHAO Dapu, CHEN Zhiyao, ZHONG Jin, NI Yixin, "A survey on ancillary in deregulated electricity market environment” Electric Power, vol.40, pp. 80-84, 2007.

[2] Huang Yonghao, Shang Jincheng, Kang Chongqing, "An Operation Mechanism and Model of Ancillary Service Market” Automation of Electric Power Systems, vol.27, pp. 33-36, 2003.

[3] HUA Xia, LUO Fan, ZHANG Jianhua, "Feasibility analysis of trade mode promoting new energy consumption based on generation rights trade of self-generation power plants" Automation of Electric Power Systems , vol.40, pp. 200-206, 2016.

[4] Chai Aijun,"Research on Ancillary Service for Generation Companies in Northwest Grid". North China Electric Power University, 2012.

[5] KONG Qiang, "Study on Evaluation and Compensation Ancillary Service in Power Market" Hunan University, 2013.

[6] XIE Guohui, LI Qionghui, "Research on calculating model and empirical analysis of power ancillary service cost" Electric Power, vol.44, pp.82-85, 201.

[7] HU Junfeng, "The Model of Cost Allocation Mechanism of Ancillary Services for Wind Integration” North China Electric Power University, 2014.

[8] LIU Wenying, WEN Jing, XIE Chang, "Multi-objective optimal method considering wind power accommodation based source-load coordination" Proceedings of the CSEE, vol.35, pp. 35-45, 2015.

[9] WU Yang, LIU Junyong, GAO Hongjun, "Research on Power Generation Right Trading Between Wind Power and Thermal Power Based on Risky Decision-Making" Power System Technology, vol.40, pp.833-839, 2016. 